e-ISSN: $1984-4255 \quad$ ARGUMENTOS

D0I: https://doi.org/10.36517/Argumentos.24.5

\title{
O curso do pensamento procleano na filosofia árabe
}

\section{The course of proclean thought in arabic philosophy}

\author{
Francisca Galiléia Pereira da Silva \\ Orcid: https://orcid.org/0000-0002-8001-2129 - E-mail: galileia@ufc.br \\ Suelen Pereira da Cunha \\ Orcid: https://orcid.org/0000-0002-7062-7971 - E-mail: suelenldp2011@gmail.com
}

\begin{abstract}
RESUMO
Caracterizados pela busca por conhecimento e pela tentativa de conciliar Filosofia e Religião, os filósofos da falsafa foram fortemente influenciados pelo pensamento grego. Contribuíram, com suas traduções, comentários e leituras interpretativas, não só para a conservação da filosofia grega como, também, para uma releitura desta no mundo latino. Neste sentido, no presente trabalho, realiza-se um exame de como as teses filosóficas de Proclo foram recebidas e incorporadas pelos falāsifa elaborando, logo de início, uma exposição do modo como pensamento grego chegou até os árabes. Em seguida, é analisada a presença dos argumentos do Bizantino entre os filósofos árabes, destacando as características que adquiriram e forma como foram incorporados em vista do propósito de adequação ao contexto islâmico. Objetiva-se, por fim, demonstrar as particularidades da presença da filosofia procleana entre os árabes e como isto possibilitou o resgate do pensamento de Proclo no mundo latino.
\end{abstract}

Palavras-chave: Proclo. Filosofia árabe. Livro das causas. Falāsifa.

\begin{abstract}
Characterized by the search for knowledge and the attempt to harmonize Philosophy and Religion, the philosophers of falsafa were strongly influenced by Greek thought. They contributed, with their translations, comments and interpretative readings to the conservation of Greek philosophy and to its reinterpretation in the Latin world. Therefore, in this work, we present an examination of how Proclu's philosophical theses were received and incorporated by
\end{abstract}


faläsifa. So, it begins with an exposition of the way in which Greek thought reached the Arabs emphasizing, specifically, the Proclean writings. Then, the presence of Byzantine arguments among Arab philosophers is analyzed, highlighting the characteristics they acquired and how they were incorporated considering the purpose of adapting to the Islamic context. Thus, the objective is to demonstrate the particularities of the presence of Proclean philosophy among the Arabs and how this enabled to the recovery of Proclu's thought in the Latin world.

Keywords: Proclus. Arab philosophy. Book of the causes. Falāsifa.

\section{Introdução}

Para compreender como se deu o processo no qual os escritos de Proclo, ou as teses procleanas, chegaram às mãos dos filósofos da falsafa, é fundamental a observação de três eventos muito significativos na história do curso dos estudos gregos e que ocorreram quase simultaneamente. O primeiro deles é o fechamento da Escola dos persas, em Edessa, em 489 d.C., pelo imperador Zenão (474 - 491d.C.) sob a justificativa de ser muito presente, nela, as tendências nestorianas - o que resultava em inúmeros problemas com as autoridades eclesiásticas na Síria. Fundada no período no século II e, posteriormente, dirigida por Efrém da Síria (306-373 d.C.), a Escola de Edessa consistia em um grande centro de estudos teológicos no qual estavam presentes os cristãos do Oriente, sendo, por isto, apropriado afirmar que a literatura siríaca tenha sido de criação cristã. Depois de seu fechamento, em 489, os ex-alunos da escola e Narsai, que tinha sido seu diretor ao longo de vinte anos na primeira metade do séc.V, se refugiaram em Nísibis, interior do Império sassânida, onde desenvolveram estudos cujas reflexões estavam voltadas à Filosofia e à Teologia.

O segundo evento ocorreu no lado sul do Império iraniano, mais precisamente, em Gondishapur, onde os sassânidas do imperador Cosroe o Grande (521-579 d. C.) formam uma nova escola na qual a maioria de seus mestres eram sírios. A escola de Gondishapur foi constituída, em grande parte, por nestorianos helenizados que, inicialmente, integravam a escola de Nísibis cuja relevância fez com que recebesse o título de cume da atividade intelectual do período. Como destaca Haq, "[...] with its elaborate hospital and enormous academic resources, Jundishapur came to function as the hub of exchange for the learning of Persia, Greece, Rome, Syria and, significantly, that of India" (HAQ, 1993, p.53). Enquanto isto, deu-se, em 529 d. C., o terceiro evento a ser destacado: o fechamento da escola neoplatônica de Atenas por Justiniano (482-565 d.C), de modo que sete filósofos neoplatônicos buscaram refúgio na Pérsia.

Durante esse período e graças a estes acontecimentos, foi traduzido, ao siríaco ${ }^{1}$, um considerável número de obras de Galeno (129-199/217 d.C) e da lógica de Aristóteles. Portanto, pode-se afirmar que o pensamento antigo chegou às mãos dos árabes por mediação dos povos da Síria e da Mesopotâmia. Afinal, os cristãos do oriente tinham, na região mesopotâmica, no período em que antecedeu a conquista islâmica, o centro religioso mais importante e no qual se desenvolviam múltiplas e distintas atividades culturais. Além disto, tinha-se acesso aos textos em grego, pois este era o idioma das Sagradas Escrituras, da liturgia e da cultura, de modo que as obras filosóficas (em especial, de Aristóteles e Galeno), médicas e dos sábios gregos, consti-

\footnotetext{
${ }^{1}$ Acerca do siríaco e seu papel na transmissão do conhecimento filosófico e científico da tradição grega, recomenda-se a leitura da obra: KING, Daniel. The Earliest Syriac Translation of Aristotle's Categories. Leiden: Brill, 2005.
} 
tuíram os pilares para o pensamento dos Padres da Igreja ${ }^{2}$. Com a expansão do Islã, os estudos helênicos se configuraram como uma peça fundamental para a fundação da Filosofia árabe.

Partindo da consideração desses acontecimentos, o presente trabalho visa expor como se deu a recepção do pensamento procleano na falsafa e como as teses do Diádoco foram incorporadas pelos filósofos do Islã. Para tanto, inicia-se com a explanação do modo como pensamento grego chegou até os árabes ressaltando, especificamente, os escritos procleanos. Por esta via, será possível melhor compreender as particularidades da presença dos argumentos do Bizantino entre os filósofos árabes, destacando as características que adquiriram e forma como foram trabalhados em vista do propósito de adequação ao contexto islâmico. Objetiva-se, assim, evidenciar como a maneira em que filosofia procleana foi abordada entre os falāsifa possibilitou o resgate do pensamento de Proclo no mundo latino.

\section{O contato do pensamento grego com a cultura islâmica}

O modo como os árabes entraram em contato com os textos e os estudos da Filosofia Antiga está diretamente vinculado à admiração que possuíam pela produção cultural oriunda de outros povos. A diversidade e riqueza intelectual com a qual se depararam geraram um grande estímulo para o acesso ao conhecimento produzido. Como resultado, muitos califas buscavam obter textos gregos desde Bizâncio ${ }^{3}$ sendo importante ressaltar que todo o interesse pelo conhecimento não foi fruto de uma exclusiva exigência intelectual. A recepção da filosofia grega estava relacionada ao propósito de elaborar um sistema no qual árabes e não árabes pudessem ter iguais direitos, a fim de fazer frente às frequentes crises culturais, políticas e religiosas no período de expansão do império. A Filosofia era vista, neste contexto, como a possibilidade do indivíduo, independente da revelação, adquirir o conhecimento da verdade podendo, por si mesmo, obter o caminho até a felicidade.

Vale destacar, também, que alguns estudos levam a crer que o contato dos árabes com a cultura grega ocorreu antes do século IX, quando é demarcado o início dos círculos de traduções. Embora não haja muitas referências historiográficas sobre o tema, existem evidências que podem servir de exemplo. Entre elas, tem-se: 1) a existência de um gênero de literatura comum tanto entre os gregos como nos povos semitas; 2 ) o visível interesse dos árabes pelos conhecimentos práticos como os de matemática, medicina e astronomia; 3) o contato dos muçulmanos com os teólogos cristãos que conheciam a filosofia grega e viviam na cidade de Damasco quando esta foi estabelecida a sede do califado omíada; e 4) as versões das obras filosóficas gregas realizadas pelas comunidades religiosas sírias 4 . Para que tudo isso fosse possível, foi imprescindível o cultivo da tolerância como uma das características da civilização islâmica clássica. A ânsia de conhecimento e a abertura para as diferentes fontes de saber podem ser verificadas nas seguintes palavras de Al-Kindī (m.873 d.C.):

Portanto, não precisamos ter vergonha de encontrar a verdade bonita e adquiri-la de onde quer que venha, mesmo que seja de povos e raças diferentes e distantes de nós. Não há nada antes da verdade para aqueles que buscam a verdade. A verdade não deve ser subestimada, nem quem fala dela ou quem a carrega deve ser humilhado. Ninguém foi degradado pela verdade; pelo contrário, pela verdade tudo se enobrece (AL-KINDĪ, 1986, p. 48).

\footnotetext{
${ }^{2}$ Mais informações sobre o assunto, Cf. PETERS, Francis E. "The Greek and Syriac background". In. NASR, Seyyed H.; LEAMAN, Oliver (Org.). History of Islamic Philosophy. London: Routledge, 1993. pp. 40-51.

${ }^{3}$ Para mais informações, indica-se a obra: FAKHRY, Majid. Histoire de la philosophie islamique. Trad. Marwan Nars. Paris: Cerf, 1989.

${ }^{4}$ Sobre este tema, cf. GERRERO, Rafael R. La recepción árabe del De Anima de Aristóteles: Al-Kindi y Al-Färäbī. Madrid: Consejo Superior de Investigaciones Científicas, 1992. pp. 11-24.
} 
Esta mensagem, sem dúvida, animou a criação dos círculos de traduções que se estabeleceram no interior do império paralelamente a sua expansão. Com as traduções, os árabes puderam distinguir quase todos os filósofos gregos, ainda que alguns só tenham sido conhecidos nominalmente ou por referências de outros. Entre as obras filosóficas às quais tiveram acesso e, por conseguinte, dedicaram-se à tradução, destacam-se as aristotélicas e platônicas. Com estas, os muçulmanos - inicialmente, os teólogos do Islã - encontraram uma grande fonte de conceitos filosóficos e recursos dialéticos preciosos para fundamentar suas teses. Sobre isto, Badawi afirma que o mundo árabe, prontamente, reconheceu a superioridade da ciência e filosofia gregas:

Le flot des traductions des ouvrages grecs en arabe était si puissant qu'il imposait cette vérité, et les partisans de la culture grecque eurent gain de cause avec éclat. La pénétration de la pensée grecque fut immense dans tous les domaines de la pensée arabe, même dans ceux où la résistance fut la plus vive: philologie, jurisprudence, et théologie. Le miracle grec a été reconnu par tous! (BADAWl, 1968, p.13).

Entre a herança e influência recebidas pelos filósofos árabes, sobressaiam-se as filosofias platônica, aristotélica e neoplatônica. Contudo, é preciso dizer que, no marco da falsafa, Aristóteles se destacou como o mais importante filósofo entre os antigos. Não se trata, todavia, do mesmo Aristóteles tal qual conhecemos hoje, da tradição pós-tomista, senão um Aristóteles com tendências neoplatônicas. Um dos casos que pode exemplificar esta tendência é no que respeita à Metafísica. Esta obra significou, para os falāsifa, uma espécie de teologia racional, ideia que se fortaleceu com a presença da Teologia do Pseudo-Aristóteles ${ }^{5}$ e outros textos neoplatônicos como os Elementos Teológicos ${ }^{6}$ de Proclo e o pseudo-aristotélico Livro das Causas ${ }^{7}$. Sobre isto, são esclarecedoras as palavras de D'Ancona:

The project of crowning Aristotle's metaphysics with a rational theology based on the Platonic tradition is an application of the late Neoplatonic model of philosophy as a systematic discipline, covering topics from logic to theology. We do not know whether this pattern reached the circle of al-Kindi as such or whether it was in a sense recreated. What we can say is that the attribution of a Neoplatonic rational theology to Aristotle has its origins in post-Plotinian Platonism (D'ANCONA, 2005, p. 27).

Ocorreu que, entre os árabes, os textos neoplatônicos foram difundidos de maneira muito particular. Isto se deu porque o pensamento dos filósofos neoplatônicos, em especial de Plotino (204 - 270 d.C), Porfírio (233 - 305 d.C) e Proclo (412 - 485 d.C), circularam em diversas obras que não coincidiam, necessariamente, com seus verdadeiros textos. Caracterizavam-se, antes de tudo, como importantes comentadores das obras aristotélicas, o que torna evidente a razão pela qual a compreensão dos filósofos árabes sobre o Primeiro Mestre está envolta das exegeses de Alexandre de Afrodísias (séc.III), Temistius (séc.III) e João Filoponos (490 - 570 d.C.), para citar alguns exemplos. Somado a isto, tem-se o fato dos filósofos árabes desconhecerem o processo de desenvolvimento do neoplatonismo no contexto greco-romano. Por esta razão, não puderam ter ciência completa do papel de Proclo, Damascio (458 - 550 d.C.) e Simplício (m.446 d.C.) no avanço do platonismo, ao que pese o fato de que possuíam seus textos. Tal des-

\footnotetext{
${ }^{5}$ Cf. a edição: PSEUDO-ARISTÓTELES. A teologia de Aristóteles. Trad. introd. e not. de Catarina Belo. Lisboa: Imprensa Nacional Casa da Moeda, 2010.

${ }^{6}$ Cf. a edição: PROCLUS. The Elements of Theology. $2^{\circ}$ Ed. Rev. trad. introd. e coment. de E.R. Dodds. New York: Oxford, 2004.

${ }^{7}$ Cf. a edição: ANÔNIMO. Livro das Causas. Trad. e intr. de Jan G. Joseph ter Reegen. Porto Alegre: Edipucrs, 2000. Acerca das versões desta obra, ver: TAYLOR, Richard C. "The Liber de Causis: A Preliminary List of Extant MSS". Em : Bulletin de philosophie médiévale, n. 25, 1983. pp. 63-84.
} 
conhecimento não tinha sido, por conseguinte, arbitrário por parte dos pensadores muçulmanos, quer dizer:

This latter omission was not the Muslims' own choice. In the centuries before the Muslims came in contact with that culture, the humane values of the Hellenic legacy were absorbed, transformed or discarded by Christianity. As a result, the rich hoard of scientific learning that the Catalogue reveals was transmitted almost intact to the Muslims, accompanied by a few random ethical gnomai but with little real understanding of Greek paideia, the cultural and humane ideals of Hellenism (PETERS, 1993, p. 42).

\section{Recepção e leitura de Proclo entre os árabes}

No que respeita a Proclo, ocorreu algo semelhante ao que se deu com Plotino, quer dizer, foi um dos mais estudados filósofos neoplatônicos entre os árabes, mas pouco conhecido por si mesmo: ora porque foi confundido com Aristóteles, devido ao texto do Livro das Causas; ora porque seus escritos foram mesclados com os de Alexandre de Afrodísia. Neste último caso, esclarece Endress, "Apart from propp. 77 and 98, the twenty remaining propositions have been transmitted as a whole under the title What Alexander of Aphrodisias has excerpted from the book of Aristotle entitled Theologia, i.e., the discourse on the Lordship along with five other treatises by Alexander" (ENDRESS, 2007, p. 335). De todo modo, a presença do pensamento procleano entre os falāsifa já seria verificada no interior do famoso Círculo de al-Kindī̄, na metade do século IX.

Não há uma conclusão decisiva se as atribuições, mesclas, interpretações e insertos que ocorriam nos escritos clássicos da filosofia tiveram seu início no interior da tradição islâmica ou se já vinham sendo realizadas desde a antiguidade tardia. Isto é, se aconteciam antes da chegada dos escritos ao mundo árabe ou, unicamente, a partir dos tempos de al-Kindī. Além disto, é preciso recordar que, no contexto da falsafa, não era frequente a referência nominal dos filósofos gregos. Com exceção de Aristóteles e, em alguns poucos casos, de Platão, os demais pensadores eram constantemente referenciados com o uso de expressões como "o mestre grego", ou "o grande mestre". Ou seja, quase nunca os nomes próprios, só as qualificações. Diante desta realidade, o nome de Proclo raramente foi citado entre os árabes, sendo, por vezes, identificado tão somente como um platônico tardio, em cuja metafísica estava presente uma reunião do pensamento platônico e aristotélico.

No que concerne ao Livro das Causas (do árabe Kalam fi mahd al-khair e conhecido no latim como Liber Aristotelis de expositione bonitatis purae), ele consiste em um escrito estudado como se compusesse um dos textos fundamentais da Metafísica de Aristóteles. Reunindo um conjunto de proposições nas quais estão expostos os pontos principais do sistema de processão, o texto versa sobre uma Causa Primeira da qual todos os seres procedem segundo uma ordem descendente. Trata-se, aqui, de uma obra que possui aspectos que suscitariam uma origem neoplatônica tardia, encontrando-se, nela, uma bela mescla entre a metafísica aristotélica e a neoplatônica, além de adaptações ao contexto monoteísta em que estava inserida. Destaca-se, por esta razão, como um importante conteúdo que se adequava à ideia de um Deus único; diferindo-se das concepções puramente procleanas que são, sobretudo, politeístas.

Com autoria, erroneamente, atribuída a Aristóteles, há suposições que apontam al-Kindī como o verdadeiro autor do Livro das Causas $^{9}$ e uma hipótese, proposta por Alberto Magno

\footnotetext{
${ }^{8}$ Acerca do Círculo de al-Kindī e da famosa Bayt al-Hikma, recomenda-se a leitura do estudo: PEREIRA, Rosalie H."Bayt al-Hikma e a transmissão do pensamento grego para o mundo islâmico". In: PEREIRA, Rosalie H.(org.). Busca do Conhecimento - Ensaios de Filosofia Medieval no Islã. São Paulo: Paulus, 2007. (Coleção Philosophica, v. 3). pp. 17-62.

${ }^{9}$ Em adiante, será referenciado tão somente, como $L d C$.
} 
(1206-1280), de que pudesse ser, na realidade, um escrito de Davi o Judeu (1152-1166) - o conhecido tradutor Juan de Sevilla da Escola dos tradutores de Toledo ${ }^{10}$. Mas, uma vez que Tomás de Aquino (1225 - 1274) identificou que a obra é um conjunto de sentenças extraídas dos Elementos Teológicos de Proclo, esta hipótese foi abandonada. Eis o que Tomás apresenta no Proêmio de seu Comentário sobre o Livro das Causas:

[...] em grego, encontramos um livro desse tipo pelo platônico Proclo, que contém 211 proposições e é intitulado Elementos de Teologia. E, em árabe, encontramos o presente livro, chamado Das Causas, entre os leitores latinos, [um trabalho] conhecido por ter sido traduzido do árabe e [desconhecida] sua existência em grego. Assim, parece que um dos filósofos árabes o extraiu deste livro de Proclo, especialmente porque tudo nele está contido de maneira muito mais completa e difusa naquele de Proclo. (TOMÁS DE AQUINO,1996, p. 4).

Sendo uma reunião de sentenças de forte cunho procleano, feita seja por discípulos do Diádoco ou por neoplatônicos posteriores, é preciso destacar algumas características do $L d C$ em relação a sua principal fonte: os Elementos Teológicos. Pretende-se, por esta via, evidenciar como as teses de Proclo transitaram no ambiente da falsafa a partir do que é apresentado nesse texto pseudo-aristotélico. Tem-se, portanto, e em primeiro lugar, que o LdC é constituído por 31 proposições ao passo que os Elementos Teológicos possui 211, apresentando uma disposição de sentenças distinta do modo como configura nos Elementos Teológicos. Ademais, nada da primeira parte dos Elementos Teológicos é utilizado na composição do texto do $L d C$. Nesta primeira parte da obra, Proclo se destina a discorrer, ao longo das proposições 1 a 112, acerca das leis metafísicas e da hierarquia dos princípios. Embora não se saiba, ao certo, o motivo da ausência de qualquer das proposições desta parte do texto, se pode afirmar, conforme Badawi, que:

Le style árabe du liber de Causis (al-Kḥayr al-Maḥd) est très beau, ses phrases sont d'un bon style, et ne révèlent aucune gaucherie étrangère. C'est un style plus beau que celui d'al-Fārābī et a fortiori que celui d'Avicenne. Il nous fait penser surtout au style de Hunain ibn Isḥāq et son fils Isḥāq. (BADAWI, 1968, p. 70).

O texto $L d C$ não é, tampouco, de todo uniforme. Isto é, há proposições que se configuram como união de vários temas tratados em momentos distintos dos Elementos Teológicos e, igualmente, há outras que consistem em cópias quase literais do texto procleano. Além da clara referência aos Elementos Teológicos, D’Ancona chama a atenção ao fato de que

Quatorze propositions du De Causis sur 31 [32] présentent des affinités avec des passages des Plotiniana Arabica. Ces affinités sont assez uniformément présentes jusqu'à la proposition 24[25], mais absentes de la partie finale du Liber. Jusqu'à la proposition 24[25], les échos des Plotiniana Arabica se regroupent autour des propositions 2-8[9] et 15[16]-24[25]. (D'ANCONA, 1995, p. 38).

Quer dizer, o autor do $L d C$ não só demonstra ter conhecimento do texto do Plotino árabe (em especial, da Teologia do Pseudo Aristóteles ${ }^{11}$ ) como o mescla com as ideias procleanas. Não se pode deixar de mencionar, também, que existem alterações do texto original dos Elementos Teológicos de acordo com interesses que se distinguem do pensamento procleano. Como exemplo, pode ser citada a proposição IV do $L d C$ que, logo no início, afirma: "37. A primeira das coisas criadas é o ser e antes dele não existe outra coisa criada" (Livro das Causas, prop. IV). Esta proposição, que possui claras modificações, corresponderia à proposição 138

\footnotetext{
${ }^{10}$ Mais informações acerca das investigações sobre a verdadeira autoria do $L d C$ podem ser encontradas em HERNANDEZ, Miguel Cruz. El neoplatonismo y el punto de partida de la filosofia árabe. In: Miscelánea de Estudios. Granada: Universidad, 1974. p. $237-246$.

11 Sobre este texto, recomenda-se o estudo: D'ANCONA, Cristina (org.). Plotiniana Arabica (Pseudo-Teologia di Aristotele), capitoli 1 e 7; "Detti del sapiente Greco", Padova: Poligrafo, 2003.
} 
dos Elementos Teológicos que, em seu enunciado, declara: “De todos os princípios que participam do caráter divino e são assim divinizados, o primeiro, o mais elevado, é o Ser" (Elementos Teológicos, prop.138).

Constata-se, aqui, que o autor do $L d C$ transforma a ideia de processão e participação da primeira realidade que procede do Uno (o Ser) em criação. Esta perspectiva criacionista não está, de maneira alguma, de acordo com as teses da metafísica procleana. Ela foi inserida, provavelmente, a fim de adequar-se aos interesses da religião criacionista e monoteísta, como bem destaca Reegen:

A primeira das afirmações próprias do $L d C$ - e da sua fonte - tem razão de ser, sem dúvida, no monoteísmo, característico tanto do islamismo quanto do cristianismo: o primeiro princípio cria, ou, o Uno original plotiniano e procliano torna-se o Deus Criador, absoluto e incondicional de todas as coisas, um Deus inteligente, todo poderoso que exerce uma providência universal.(...) Em afirmar, categoricamente, a criação, desaparece qualquer possibilidade de pensamento em processão ou emanação, tão característica para o pensamento neoplatônico, tanto de Plotino como de Proclo. Ao afirmar a criação, que deve ser entendida no sentido de produzir ex nihil, por parte da Causa Primeira, o LdC se distancia, então, tanto de Plotino quanto de Proclo porque faz do Primeiro Princípio o Ser Puro, que é a causa de todos os seres e, enquanto tal, de todos eles diferente e transcendente. (REEGEN, 2000, p. 87).

Acerca da adequação ao contexto, ressalta-se que a atribuição do $L d C$ a Aristóteles também não é por acaso ou, simplesmente, devido a um desconhecimento, seja da estrutura ou característica da escrita aristotélica seja da filosofia neoplatônica. Ela é resultado da proposta de conciliar Filosofia e Religião, compreendendo a primeira como algo que pode dar suporte teórico racional às doutrinas da segunda. A tendência de neoplatonizar Aristóteles, mesclando suas teses com as do pensamento neoplatônico ou mesmo atribuindo uma autoria aristotélia a textos de matriz neoplatônica, era frequente na Filosofia Árabe. Isto se deve, em grande parte, à tentativa de conciliar o conteúdo filosófico e a religião islâmica, pois busca realizar uma articulação entre os pensamentos de Platão e Aristóteles, no qual o primeiro é compreendido como divino enquanto o segundo, o sábio.

Discorrendo, especificamente, quanto a atribuição de Aristóteles como autor do $L d C$, ela se configura a partir de duas justificativas principais: a primeira diz respeito ao fato de Aristóteles ter sido compreendido como a razão personificada. Portanto, o que estivesse de acordo com as diretrizes do Estagirita estaria conforme a razão mesma. A segunda pode ser explicada como um desejo de encontrar uma teologia que completasse o que é exposto por Aristóteles na Metafísica, particularmente, no livro $\Lambda$, marcado pela relação de dependência das coisas sensíveis a uma causa ulterior ${ }^{12}$. Neste sentindo, como explica Reegen, seria possível

afirmar que a lei da primazia causal do Uno que governa, pensamento central do $L d C$, pode ser aplicada a um primeiro princípio que possui este mesmo caráter e que consta da teologia aristotélica do referido livro $\Lambda$ e que, além disso, é exigida pela fé. Neste caso, a causalidade de Deus age, então, ao mesmo tempo como o Uno neoplatônico, onipresente por sua irradiação, e como NOY $\Sigma$ divino da metafísica aristotélica. (REEGEN, 2000, p. 84).

Poder-se-ia perguntar por que um movimento semelhante não se deu com Platão. Quer dizer, por que, na tentativa de uma fundamentação filosófica da religião, não se encontrava, nas obras do mestre de Aristóteles, um suporte equivalentemente forte. A resposta para tanto está vinculada ao fato de que, ainda no ambiente cristão, Alexandria e Atenas seguiam, com suas escolas neoplatônicas, uma tradição de comentários das filosofias de Platão e Aristóteles.

\footnotetext{
${ }^{12}$ Cf. a edição: ARISTÓTELES. Metafísica. Trad. Giovanni Reale. Vol.II. São Paulo: Loyola, 2002. p. 541-586.
} 
Entretanto, no século VI, as discussões mais frequentes em Alexandria versavam sobre Aristóteles ao mesmo tempo que o neoplatonismo pagão ficava de fora da escola. Esta propensão à redução dos estudos de Platão em ambiente cristão, onde tais estudos eram desenvolvidos, está estreitamente relacionada aos escritos procleanos.

Aconteceu que, no ambiente cristão, o escrito procleano Sobre a eternidade do mundo ${ }^{13}$ emergiu como uma ameaça à doutrina criacionista cristã por conter 18 teses anti-criacionistas. E, como o Diádoco ficou conhecido somente como um sucessor do pensamento de Platão, embora não tenha se restringido a fazer comentários dos diálogos platônicos, seu escrito resultou no banimento dos estudos da filosofia platônica naquele contexto. Mesmo tendo, prontamente, uma refutação feita por João Filoponos, no seu Sobre a eternidade do mundo contra Proclo $^{14}$, verificou-se que,

Especially after 529, the date of ban on public teaching by philosophers of pagan allegiance, it would have been daring give courses on the 'theological' dialogues by Plato, whose interpretation, especially after Proclus, was strongly committed to polytheism (D'ANCONA, 2005, p. 17).

Por esta razão, ao passo que obra de João Filoponos foi vastamente utilizada tanto na tradição cristã quanto na muçulmana, a leitura de Platão e, por conseguinte, de Proclo ficou comprometida. Reflexos destes acontecimentos influenciaram o modo como estes pensadores foram recebidos na cultura islâmica. Porém, ao contrário de pensar que suas teses não foram conhecidas, o que se observa é que consistiram em grandes contributos, deixando fortes marcas na filosofia árabe. Por esta via, mesmo que, raramente, os filósofos neoplatônicos fossem expressos por si mesmos, as ideias neoplatônicas e, em específico, de Proclo, foram grandemente utilizadas pelos falāsifa.

\section{O que, na filosofia procleana, tanto atraiu os pensadores árabes?}

Constata-se que a mesma reflexão filosófica que contribuiu para a fundamentação do Deus uno e trino, durante os primeiros séculos de expansão do cristianismo, configurou-se em um elemento precioso à teologia e à filosofia islâmicas. Oferecendo um reforço filosófico aos atributos de Allāh presentes no Corão, as teses neoplatônicas que apontam para uma realidade superior, em si e, absolutamente, Una auxiliaram na defesa da assertiva de que o Deus corânico é verdadeiro. Ademais, tendo em vista que uma das ideias mais presentes no $L d C$ é a definição de uma realidade Una, cuja unicidade é a base de tudo o que existe sem que nada possa interferir na sua grandeza ou mesmo tenha sua plenitude oriunda de outro princípio ${ }^{15}$, ela se encaixa, perfeitamente, à compreensão de Deus como estritamente singular (tawhid); único (wahid) e, intrinsecamente, $\mathrm{Um}$ ( (had $)^{16}$. Nesta perspectiva, a razão atestada pela filosofia grega em nada, conflitava com a descrição de um Deus supremo ou, como observamos no Corão, com Aquele que "Não há divindade além d'Ele, o Vivente, o Auto-Subsistente" (Corão, 3: 2).

\footnotetext{
${ }^{13}$ Cf. a edição: PROCLUS. On the eternity of the world. Ed. Bilingue. Trad. introd. e com. de Helen S. Lang. London: University of California Press. 2001.

${ }^{14}$ Cf. as edições: PHILOPONUS. Against Proclus On the eternity of the world 1-5. Trad. Michael Share. Londres: Bloomsbury Academic Press, 2005.; PHILOPONUS. Against Proclus On the eternity of the world 6-8. Trad. Michael Share. Londres: Bloomsbury Academic Press, 2005.; PHILOPONUS. Against Proclus On the eternity of the world 9-11. Trad. Michael Share. Londres: Bloomsbury Academic Press, 2010; PHILOPONUS. Against Proclus On the eternity of the world 12-18. Trad. James Wilberding. Londres: Bloomsbury Academic Press, 2006.

${ }^{15} \mathrm{Cf}$. prop. XIX do Livro das Causas, que concorda com a prop. 116 dos Elementos Teológicos.

16 "1. Dize: Ele é Allah, o Único!; 2. Allah! O Absoluto!; 3. Jamais gerou ou foi gerado!; 4. E ninguém é comparável a Ele!” (Corão, 112: 1-4).
} 
Lembrando, muitas das proposições procleanas chegaram aos árabes de maneira fragmentada: seja atribuídas a Alexandre de Afrodísia, seja como parte do LdC. Não obstante isto, o estilo e a terminologia presente na redação das traduções sugerem que elas tenham sido todas realizadas no mesmo ciclo dos primeiros tradutores. No caso do $L d C$, costuma-se atribuir a primeira tradução a Isḥāq ibn Ḥunain (809-873 d.C.), o mesmo que traduziu o escrito procleano Sobre a eternidade do mundo. Porém, existe a hipótese de que, em realidade, a primeira versão do $L d C$ seja em árabe, uma vez que nunca foi encontrada qualquer referência deste texto em grego. Por esta razão, Tomás de Aquino, no proêmio de seu Comentário, afirma a inexistência do escrito em grego. De todo modo, independente da forma como as teses procleanas foram inseridas na cultura árabe, constata-se, entre as presentes nos Elementos Teológicos, que

The twenty two propositions extant in Arabic translation cover the properties of the immaterial forms (EI TheoL, prop. 15-17), the relationship of the One and the many (prop. 21), eternity and time (prop. 54), being, forms, and the whole (prop. 62, 72, 73, 74), unmoved and moving causes (prop. 76), perfect and imperfect potency (prop. 77-79), bodies and incorporeal agents (prop. 80, 86, 91), the transcendence and immanence of separate causes (prop. 98), and the hierarchy of intelligences (prop. 167). (ENDRESS, 2007, p. 336).

Isso sem contar as que se encontram, mesmo com alterações, no $L d C$. Deste, são verificados traços, referências e comentários em textos de diferentes filósofos do Islã. Entre eles, podem ser citados al-Fārābī (875-950) que, no livro A questão principal ('Uyun al-Masa'il), trata sobre a categoria de processão e apresenta uma espécie de resumo do $L d C$, discorrendo, em sentido geral, sobre os mesmos problemas, além de concordar com o texto ${ }^{17}$. Pode-se mencionar, também, uma clara influência na primeira parte da Cidade Ideal (Al-madinnat al-fädila) ${ }^{18}$ quando o filósofo desenvolve seu sistema cosmológico estruturado a partir da processão de uma Causa Primeira, una, originária de toda a multiplicidade dos seres. O mesmo é possível ser observado na primeira parte de seu Livro da política (Kitāb al-siyāsa al-madaniyya) ${ }^{19}$, quando discorre acerca dos princípios dos seres. Ademais, Ibn al-Nadim (m. 990) menciona, em seu importante Catálogo (Fihrist) - no qual realiza um registro dos filósofos árabes e dos escritos clássicos que eram estudados no início do desenvolvimento da falsafa - que existe uma obra chamada $O$ Primeiro Bem entre os textos de Proclo, o que seria uma possível referência ao $L d C$. Além deste texto, al-Nadim elenca outros escritos procleanos que teve conhecimento, como se pode ler no seguinte trecho do Catálogo:

Diádoco Proclo, do povo de Ataleia, o platônico: Definição das origens dos fenômenos naturais [Elementa physica]; As dezoito perguntas [Duodevingiti quaestiones siva argumenta Christianos], que Yahyā al-Nahwī refutou; Exposições da declaração de Platão de que a alma não é a essência [Commentarius in Platonis dialogum de anima immortalitate]; Teologia [Institutio theologica], que pertence a Deus; Comentário sobre os testamentos de ouro de Phytagoras [em Pythsgorae aurea carmina commentarius] - possui cerca de cem folhas e existe em siríaco. Ele o escreveu para a filha. Thābit [ibn Qurrah] traduziu três de suas folhas, mas [em seguida] morreu, de modo que ele não a completou. Os elementos sublimes; livro de Proclo, chamado Diádoco, que é "o seguidor de Platão", sobre Dez perguntas [De decem quaestionibus, sive dubitationibus circa providentiam]; O Primeiro Bem; As dez perguntas difíceis [Decem dubitationes circa providentiam]; O átomo que não pode ser dividido; $O$ esclarecimento que Platão deu em seu livro intitulado 'Górgias' [De parabola, quato Platão em

\footnotetext{
${ }^{17}$ Acerca deste texto, incluindo o questionamento sobre a autenticidade da autoria de al-Fārābī, cf. AL-FARABI, Abu Nasr. Fontes quaestionum. ed. Miguel Cruz Hernandez. Archives d'Histoires doctrinale et litéraire du Moyan Âge. Vol. 25-26. p. 303-323, 1950-1951.

${ }^{18}$ Cf. a edição: ALFARABI, Abu Nasr. A cidade virtuosa. Trad. Catarina Belo. Lisboa: Calouste Gulbenkian, 2018.

${ }^{19} \mathrm{Cf}$. a edição: AL-FĀRĀBIT, Abu Nasr. “Libro de la Política”. In: Obras filosóficas y políticas. Ed. e trad. de Rafael Ramón Guerrero. Madrid: Trotta, 2008.
} 
dialogo, qui Górgias inscribitur, protulit], em siríaco; Comentário sobre a décima seção sobreo acontecimento que aparece em siŕ́aco; o livro de Proclo, o platônico, intitulado Estoicismo menor; o livro de Proclo sobre um comentário acerca do Fédon, sobre a alma - Abū'Alī [lsa ibn Īshāq] ibn Zur'ah traduziu uma pequena parte dele para o árabe. (AL-NADIM, 1970, p. 607).

Pode ser citada, também, a presença de elementos das teses vistas no $L d C$ em escritos de Ibn Sīnā (980-1030). Em seu texto A origem e o retorno (Al-Mabda' wa al-Ma'äd), em especial, entre os capítulos VIII a XIV, verifica-se o desenvolvimento de argumentos que, relacionando as categorias de ser necessário e seres possíveis, destacam como os segundos se originam do primeiro. Ressalta, neste momento, a defesa da unicidade do ser necessário, como pura unidade absoluta, não sendo admitida, de forma alguma, qualquer divisão de sua essência ${ }^{20}$. Aqui, é importante salientar que, a despeito da verificação da influência do $L d C$ tanto nas obras de al-Fārābī quanto nas de Ibn Sīnā, não há menção, ao menos nos escritos que chegaram até nós, do nome de Proclo. Isto, sem dúvida, termina por ser um fator delimitante no real entendimento do quão este filósofo tardio foi conhecido pelos falāsifa. Entretanto, o fenômeno da ausência de referência nominal direta, como já mencionado neste texto, é característico entre os filósofos do Islã - resguardando em alguns casos, as figuras de Platão e Aristóteles.

Menciona-se, ainda, com base no que nos informa Peters ${ }^{21}$, a evidência da posse de um resumo do $L d C$ por 'Abd al-Latīf ibn Yūsuf al-Baghdādī (1162-1231), algo que corresponderia a uma tradução de Abū 'Uthmān al-Dimashqī (m. 914). Na seção XX da Ciência Metafísica'² de al-Baghdādī, observa-se que há uma menção tanto à prop.54 dos Elementos Teológicos quanto ao texto Exposição do Bem, atribuindo-o a Aristóteles, ou, mais precisamente, ao "Sábio"23. Neste caso preciso, esta seria a referência expressa mais antiga ao $L d C$, citando suas passagens e realizando um breve resumo do texto. Igualmente, Ibn Abī Ușaybi' a (1203 - 1270) o assinala sob o título Exposição do bem puro. Em seu História dos médicos (Uyun al-Anba), o insere na lista de obras aristotélicas desconhecidas por Ptolomeu mas que ele (Ușaybi 'a) obteve conhecimento ${ }^{24}$. Por fim, Ibn Sab'in (1216-1271) mencionou em seu Questões sicilianas (Al-Kalam 'ala al- masa'ilal-siqiliyah) como $O$ bem puro, atribuindo-o a Aristóteles ${ }^{25}$.

Entende-se, portanto, que, ao falar sobre as teses procleanas durante o medievo árabe, não é possível deixar de pôr em relevo o texto do $L d C$. Afinal, quando este escrito dá ao sistema henológico do Bizantino contornos criacionistas, ele torna aceitáveis as ideias de Proclo em contexto monoteísta. Além disto, ao outorgar a autoria da obra a Aristóteles, o autor do LdC potencializou, ainda mais, a inserção das proposições procleanas na filosofia árabe. Ou seja, o pensamento procleano presente no $L d C$ serviu como base para uma fundamentação racional de uma Causa Primeira na filosofia árabe. Mas não somente isto, também ofereceu uma garantia filosófica de que a fé islâmica estava em total equivalência com o logos grego.

\section{Conclusão}

Constata-se, conforme o exposto, que o $L d C$ terminou por traduzir-se em um suporte para que os filósofos árabes desenvolvessem suas reflexões sem que sugerisse um conflito ou

${ }^{20} \mathrm{Cf}$. a edição: IBN SĪNĀ. A origem e o retorno. Trad. de Jamil Ibrahim Iskandar. São Paulo: Martins Fontes, 2005.

${ }^{21}$ Cf. PETERS, Francis E. The origins of Islamic Platonism: the school tradition. New York: New York University Press, 1979. p. 65.

${ }^{22}$ Acerca desta obra, recomenda-se a leitura do livro BONADEO, Cecilia M. 'Abd al-Latîf Yūsuf al-Baghdādi's philosophical journey from Aristotle's Metaphysics to the 'Metaphysical science'. Leiden: Brill, 2013.

${ }^{23}$ Cf. BADAWI, Abdurrahman. La transmission de la philosophie grecque au monde arabe. Paris: VRIN, 1968. p. 67.

${ }^{24}$ Cf. a edição: UȘAYBI'A, Ibn Abī. History of physicians. Trad. L. Kopf. Israel: National Library of Medicine, 1971. p. 136. A versão Online desta obra está disponível em: http://www.tertullian.org/fathers/ibn_abi_usaibia_01.htm\#PREFACE. Acesso em: 05 de maio de 2020.

${ }^{25}$ Cf. a edição: SAB'İN, Ibn. Las cuestiones sicilianas. Trad. Luísa Maria Arvide. Granada: Editorial GEU, 2010. 
oposição entre fé e razão. A tudo isto se soma o fato, já mencionado, de que o $L d C$ foi tido como parte do livro $\Lambda$ da Metafísica. A referência a Aristóteles, como afirmado anteriormente, era um reforço significativo a uma legitimação racional do conteúdo religioso. Logo, o $L d C$ oferece, ao medievo de tradição monoteísta, uma ideia criacionista que está em perfeito acordo com a razão. Mediante ele, os argumentos procleanos presentes nos Elementos Teológicos passam a se configurar como um forte contributo para uma interpretação monoteísta e criacionista da filosofia aristotélica neoplatonizada no mundo árabe.

Atesta-se, por fim, que há uma referência à influência dos textos e argumentos procleanos no contexto árabe desde o século VI da hégira. Em vista disto, a despeito do possível desconhecimento nominal de Proclo, o conteúdo da filosofia procleana que se apresenta em meio aos escritos dos pensadores do Islã demonstra que o interesse dos árabes pela filosofia do Diádoco foi maior do que o que eles puderam perceber. Não obstante as hipóteses acerca da autoria, não se pode ignorar que, como alerta Ramón Guerrero e como supracitado, o $L d C$ só é referenciado, diretamente, "por dos autores árabes del siglo XIII, se ha supuesto que fue obra de un personaje desconocido de Toledo, quizá de origen judío del siglo XII, puesto que fue en esta época cuando apareció traducido en latín" (GUERRERO, 1985, p. 50).

Ainda que a autoria de $L d C$ permaneça desconhecida, sua filiação às teses procleanas são inegáveis. Desta maneira, o texto trouxe, aos pensadores da falsafa, a filosofia de um autor que, até o século XII, foi negado ou mesmo ignorado pelos cristãos do ocidente. A desconfiança de Tomás de Aquino acerca da legitimidade da autoria aristotélica do $L d C$ foi o primeiro passo que possibilitou que o pensamento de Proclo adentrasse no mundo latino, via Faculdade de Artes de Paris. Isto é, mesmo sem grandes referências diretas, a presença das ideias do Bizantino nos escritos árabes e, destacadamente, no $L d C$, foi o que tornou possível sua introdução no mundo latino durante o século XIII, fazendo reviver, em solo cristão, as ideias do Sucessor Platônico.

\section{Referências bibliográficas}

ALCORÃO. Trad. Samir el Hayek.14a ed. São Paulo: MarsaM, 2009.

AL-FĀRĀBĪ, Abu Nasr. A cidade virtuosa. Trad. Catarina Belo. Lisboa: Calouste Gulbenkian, 2018.

AL-FĀRĀBĪ, Abu Nasr. Fontes quaestionum. Ed. Miguel Cruz Hernandez. Archives d'Histoires doctrinale et litéraire du Moyan Âge. Vol. 25-26. pp.303-323, 1950-1951.

AL-FĀRĀBĪ, Abu Nasr. "Libro de la Política". In: Obras filosóficas y políticas. Ed. e trad. de Rafael Ramón Guerrero. Madrid: Trotta, 2008.

AL-KINDĪ. Obras filosóficas. Trad. introd. e not. de Rafael Ramón Guerrero e Emilio Tornero Poveda. Madrid: Coloquio, 1986.

AL-NADIM, Muhammad ibn Ishaq. The Fihrist of al-Nadim - a tenth-century survey of muslim culture. Trad. e ed. de Bayard Dodge. Vol. I. New York: Columbia University Press, 1970. p. 607.

ARISTÓTELES. Metafísica. Trad. Giovanni Reale. Vol. II. São Paulo: Loyola, 2002.

BADAWI, Abdurrahman. La transmission de la philosophie grecque au monde arabe. Paris:VRIN, 1968. BONADEO, Cecilia M. 'Abd al-Latîf Yūsuf al-Baghdādì's philosophical journey from Aristotle's Metaphysics to the 'Metaphysical science.' Leiden: Brill, 2013.

D'ANCONA, Cristina (Org.). Plotiniana Arabica (Pseudo-Teologia di Aristotele), capitoli 1 e 7; "Detti del sapiente Greco". Padova: Poligrafo, 2003. 
D'ANCONA, Cristina. Recherches sur le liber de causis. Paris: Vrin, 1995.

ENDRESS, G. "Building the library of Arabic Philosophy Platonism and Aristotelism in the sources of al-Kindī". In: D'ANCONA, Cristina (Org.). The Libraries of the neoplatonists. Leiden: Brill, 2007.

FAKHRY, Majid. Histoire de la philosophie islamique. Trad. Marwan Nars. Paris: Cerf, 1989.

GUERRERO, Rafael R. “El compromiso político de Al-Fārābī ¿Fue un filósofo šî́ ?".Em: Actas de las II Jornadas de cultura Árabe e Islamica (1980). Madrid: Isntituto Hispano-arabe de cultura, s/informações, 1985. pp. 463-477.

GUERRERO, Rafael R. La recepción árabe del De Anima de Aristóteles: Al-Kindi y Al-Fārābī. Madrid: Consejo Superior de Investigaciones Científicas, 1992.

HAQ, Syed N. “The Indian and Persian Background”. In: NASR, Seyyed Hossein; LEAMAN, Oliver (Org.). History of Islamic Philosophy. London: Routledge, 1993.

HERNANDEZ, Miguel Cruz. "El neoplatonismo y el punto de partida de la filosofia árabe". In: Miscelánea de Estudios. Granada: Universidadde Granada, 1974. pp.237- 246.

IBN SīNĀ. A origem e o retorno. Trad. de Jamil Ibrahim Iskandar. São Paulo: Martins Fontes, 2005. KING, Daniel. The Earliest Syriac Translation of Aristotle's Categories. Leiden: Brill, 2005.

PEREIRA, Rosalie H."Bayt al-Hikma e a transmissão do pensamento grego para o mundo islâmico". In: PEREIRA, Rosalie H.(org.). Busca do Conhecimento. Ensaios de Filosofia Medieval no Islã. São Paulo: Paulus, 2007. (Coleção Philosophica, v. 3). pp.17-62.

PETERS, Francis E. "The Greek and Syriac background". In: NASR, Seyyed H.; LEAMAN, Oliver (Org.). History of Islamic Philosophy. London: Routledge, 1993.

PETERS, Francis E. The origins of Islamic Platonism: the school tradition. New York: New York University Press, 1979.

PHILOPONUS. Against Proclus On the eternity of the world 1-5. Trad. Michael Share. Londres: Bloomsbury Academic Press, 2005.

PHILOPONUS. Against Proclus On the eternity of the world 6-8. Trad. Michael Share. Londres: Bloomsbury Academic Press, 2005.

PHILOPONUS. Against Proclus On the eternity of the world 9-11. Trad. Michael Share. Londres: Bloomsbury Academic Press, 2010.

PHILOPONUS. Against Proclus On the eternity of the world 12-18. Trad. James Wilberding. Londres: Bloomsbury Academic Press, 2006.

PROCLUS. On the eternity of the world. Ed. Bilingue. Trad. untrod. e com. De Helen S. Lang. London: University of California Press. 2001.

PROCLUS. The Elements of Theology. $2^{\mathrm{a}}$ ed. A revised Text with translation, introduction, and commentary by E.R. Dodds. New York: Oxford, 2004.

PSEUDO-ARISTÓTELES. A teologia de Aristóteles. Trad. introd. e not. de Catarina Belo. Lisboa: Imprensa Nacional Casa da Moeda, 2010.

ANÔNIMO. Livro das Causas. Trad. e intr. de Jan G. Joseph ter Reegen. Porto Alegre: Edipucrs, 2000.

REEGEN, Jan G. J. ter. "A Metafísica da Teologia do Pseudo Aristóteles". In: Anales del Seminario de Historia de la Filosofía, vol. 23. Madrid, 2006. p. 59-74.

REEGEN, Jan G. ter. «Introdução». In: PSEUDO-ARISTÓTELES. Livro das Causas. Trad. e intr. de Jan G. Joseph ter Reegen. Porto Alegre: Edipucrs, 2000. 
SAB'ĪN, Ibn. Las cuestiones sicilianas. Trad. Luísa Maria Arvide. Granada: Editorial GEU, 2010.

TAYLOR, Richard (Org.). Arabic Philosophy. Cambridge: Cambridge University, 2005.

TAYLOR, Richard. "The Liber de Causis: A Preliminary List of Extant MSS". In: Bulletin de philosophie médiévale, n.25, 1983. pp. 63-84.

TOMÁS DE AQUINO. Commentary on the Book of Causes. Trad. Vicente Gualiardo; Charles Hess e Richard Taylor. Washington: The Catholic University of America Press, 1996.

UȘAYBI'A, Ibn Abī. History of physicians. Trad. L. Kopf. Israel:National Library of Medicine, 1971. Versão Online disponível em: http://www.tertullian.org/fathers/ibn_abi_usaibia_01.htm\#PREFACE. Acesso em: 5 maio 2020.

\section{Sobre as autoras}

\section{Francisca Galiléia Pereira da Silva}

Professora da Universidade Federal do Ceará. Doutora em Filosofia pela Universidade Complutense de Madrid. (2015) e especialização em Manuscritos no Islã também pela Universidade Complutense de Madrid. Coordenadora e pesquisadora do Grupo de Estudos em Filosofia Medieval da Universidade Federal do Ceará (GEFIM-UFC). Tem experiência de docência, pesquisa e orientação de trabalhos na área de Filosofia, com ênfase em Filosofia Clássica, Filosofia Medieval Ocidental, Filosofia Árabe, Filosofia da Religião, Epistemologia, Ética e Política.

\section{Suelen Pereira da Cunha}

Professora do Instituto Federal do Ceará. Doutoranda do programa de Pós-Graduação em Filosofia da Universidade Federal do Ceará, onde desenvolve o projeto de pesquisa entitulado "A possibilidade do conhecimento na filosofia procleana". Mestra em Filosofia pela UFC e graduada em Filosofia pela Universidade Estadual do Ceará. Atua como pesquisadora no Grupo em Estudos em Filosofia Medieval (GEFIM-UFC), desde outubro de 2011, e é membro do Grupo de Pesquisa de Tradução e Recepção do Clássicos da Universidade Federal do Ceará, desde setembro de 2015.

Recebido em: 21/05/2020

Aprovado em: 18/07/2020 